\title{
Effect of bile acids on electrical properties of rat colon: Evaluation of an in-vitro model for secretion
}

\author{
E. JOSEPH SCHWITER, GERSHON W. HEPNER, AND RICHARD C. ROSE \\ From the Departments of Physiology, Medicine, and Surgery, The Milton S. Hershey Medical Center of the \\ Pennsylvania State University College of Medicine, Hershey, Pennsylvania
}

SUMMARY A preparation of rat colon mucosa has been evaluated as a useful model to study effects of bile acids on the changes in short-circuit current and transmural electrical potential difference (pd) which others have associated with alterations in electrolyte transport. Using this preparation, it was found that bile acids were effective in increasing short-circuit current and pd when applied to the serosal, but not the mucosal, surface of the tissue. Furthermore, taurine-conjugated cholic acid, which has no demonstrable effect on the colon in vivo, was found to increase short-circuit current and pd significantly in the in-vitro preparation. These data indicate the limitations of the in-vitro model in studying the mechanism of bile acid-stimulated intestinal secretion.

The pathogenesis of diarrhoea caused by bile acids, termed cholerrhoeic enteropathy (Hofmann, 1967) or cholanorrhoeic diarrhoea (Hofmann, 1973), is imperfectly understood. Dihydroxy bile acids inhibited salt and water absorption and tended to initiate fluid secretion in studies on human and hamster jejunum (Teem and Phillips, 1972; Wingate, Phillips, and Hoffman, 1973) and human and canine colon (Mekhjian and Phillips, 1970; Mekhjian, Phillips, and Hofmann, 1971). In these studies, a trihydroxy bile acid (cholic acid) was without effect.

Binder and Rawlins (1973) used an in-vitro preparation of rat colonic mucosa to study $\mathrm{Na}$ and Cl transport, short-circuit current and transmural electrical potential difference (pd). They found that taurochenodeoxycholic acid, a taurine-conjugated dihydroxy bile acid, reduced net absorption of $\mathrm{Na}$ and $\mathrm{Cl}$, and increased short-circuit current and pd: theophylline mimicked these effects and initiated secretion of $\mathrm{Cl}$. They suggested that the in-vitro preparation demonstrated changes that occur when these bile acids are exposed to the colon in vivo, and may be responsible for the pathophysiological phenomena associated with bile acid diarrhoea.

Before data from this in-vitro model can be used to understand the changes seen in vivo, it is necessary

${ }^{1}$ Please address correspondence to Richard C. Rose, PhD, Department of Physiology, The Milton S. Hershey Medical Center, Hershey, Pennsylvania 17033

Received for publication 12 March 1975. to determine what effect trihydroxy bile acid (cholic acid) may have when it is used. Cholic acid is without effect on jejunal and colonic salt and water absorption (Mekhjian and Phillips, 1970; Mekhjian et al, 1971; Wingate et al, 1973) and should be without effect in vitro if this model truly reflects in-vivo phenomena. Moreover, since bile acids are exposed in vivo to the mucosal surface of intestine, effects with the in-vitro model should occur when bile acids are exposed only to the mucosal surface of the preparation; in the study of Binder and Rawlins (1973) bile acids were applied to both the mucosal and serosal surfaces.

Since initiation of secretion by large and small intestine is accompanied by an increase in electrical activity of the tissue (Binder and Rawlins, 1973; Field, 1971), we measured changes in short-circuit current and pd of rat colon as an index of the state of secretory activity of the tissue. The taurine conjugates of the two primary bile acids, taurocholic acid and taurochenodeoxycholic acid, the taurine conjugate of deoxycholic acid, and theophylline were tested for effect at either the mucosal or the serosal surface.

\section{Methods}

Male Sprague-Dawley rats weighing $300-400 \mathrm{~g}$ were anaesthetized with ether and killed by intracardiac injection of $33 \mathrm{mg}$ of pentobarbital. The proximal half of the colon was removed and washed with 
Ringer solution at $0^{\circ} \mathrm{C}$. The serosa and part of the muscular layers were removed before mounting the tissue in the apparatus for measuring electrical properties as described previously (Rose, Gelarden, and Nahrwold, 1973). Briefly, $1.13 \mathrm{~cm}^{2}$ of tissue was held between the halves of a Lucite chamber and exposed on each surface to $15 \mathrm{ml}$ of buffered electrolyte solution at $37^{\circ} \mathrm{C}$. The composition of the Ringer solution was (mM): $\mathrm{NaCl}, 140 ; \mathrm{MgCl}_{2}, 1 \cdot 2$; $\mathrm{CaCl}_{2}, 1 \cdot 2 ; \mathrm{K}_{2} \mathrm{HPO}_{4}, 1 \cdot 2 ; \mathrm{KH}_{2} \mathrm{PO}_{4}, 0 \cdot 2 ; \mathrm{KHCO}_{3}$, 10 ; and $\mathrm{pH}$ approximately $7 \cdot 0$. The bathing solution was circulated across each surface of the tissue by means of a gas-lift circulating system driven by water-saturated $95 \% \mathrm{O}_{2}-5 \% \mathrm{CO}_{2}$.

Tips of Ringer-agar bridges were placed close to each surface of the membrane and the pd was measured using a pair of calomel electrodes leading to a high input impedance electrometer and recorded on a Beckman recorder. The tissue was shortcircuited by applying external current; tissue resistance was determined by recording the pd deflection in response to $50 \mu \mathrm{A}$ of direct current from the external battery source.

The tissue was initially incubated in Ringer solution in the absence of theophylline and bile acids. After approximately $20 \mathrm{~min}$, when the short-circuit current had stabilized, an appropriate volume of concentrated stock solution of bile acid $(20 \mathrm{mM})$ or theophylline $(100 \mathrm{mM})$ was added to one or both of the bathing solutions. The second compound was added to the existing solution $20-30 \mathrm{~min}$ after the first. When bile acid (final concentration, $2 \mathrm{mM}$ ) or theophylline (final concentration, $10 \mathrm{mM}$ ) was added only to the mucosal or the serosal bathing solution, mannitol was added to the other solution to maintain osmotic equilibrium. Bile acids were found to be at least $95 \%$ pure by thin-layer chromatography. Changes in short-circuit current and pd are reported as the difference between the recorded peak value after the addition of bile acid or theophylline and the value observed immediately before addition.

\section{Results}

\section{BILE ACIDS}

The addition of taurochenodeoxycholic acid ( $2 \mathrm{mM})$ to the mucosal and serosal bathing solutions of rat colon, or to the serosal solution alone, caused an increase in short-circuit current and pd which occurred within two min (fig 1A; table I). Applied to the mucosal surface alone, taurochenodeoxycholic acid was without effect (fig 1B). When taurochenodeoxycholic acid was added to the mucosal and/or serosal solution after the addition of $10 \mathrm{mM}$ theophylline there was no increase in short-circuit current. Similar results were obtained when taurodeoxycholic acid was used in place of taurochenodeoxycholic acid. Following inhibition of active transport processes and reduction of the transmural pd to zero by the application of cyanide $(1 \mathrm{mM})$ or by anaerobic conditions, there was no effect on pd or short-circuit current due to taurodeoxycholic acid in both bathing solutions.

A significant decrease in tissue resistance was noticed with taurochenodeoxycholic acid.

Taurocholic acid $(2 \mathrm{mM})$ added to the mucosal and serosal solutions of colon, or to the serosal solution alone, caused an increase in short-circuit current and pd (fig 1C, table II). The increase in short-circuit current seen when taurocholic acid was added to the serosal solution $\left(27 \pm 5 \mu \mathrm{a} / \mathrm{cm}^{2}\right)$ was significantly smaller than the increase seen with taurochenodeoxycholic acid $(P<0.05)$. When taurocholic acid was added to the mucosal solution there was no effect on short-circuit current (fig 1D).

\section{THEOPHYLLINE}

Theophylline increased short-circuit current and pd whether applied to both surfaces of the colon or to

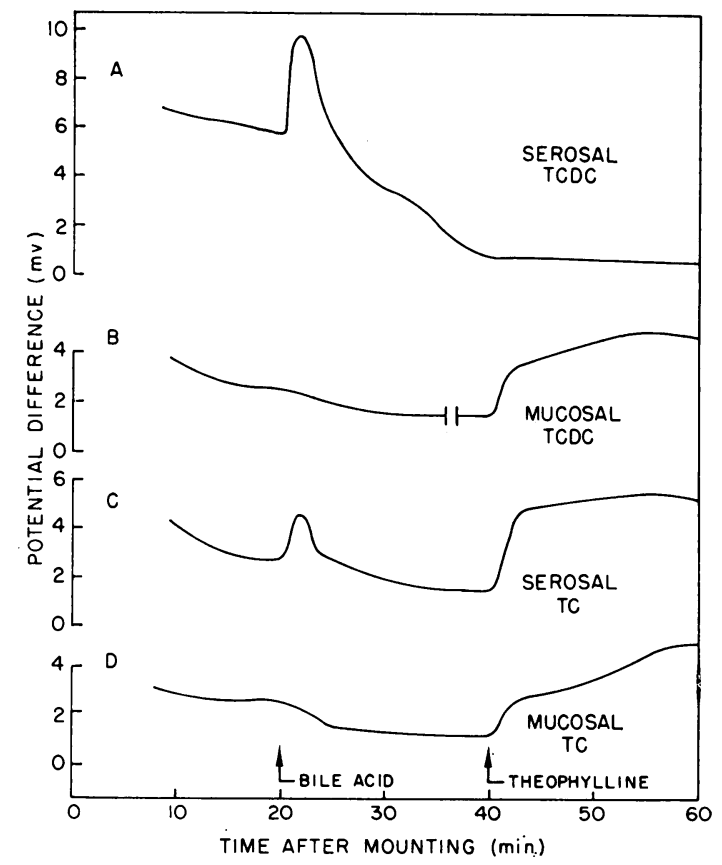

Fig 1 Representative experiments showing the effect of mucosal and serosal applications of taurochenodeoxycholic acid, taurocholic acid, and theophylline on pd of rat colon. Bile acid ( $2 \mathrm{mM})$ was added approximately 20 min after the tissue was mounted and theophylline (10 $\mathrm{mM}$ ) was added after 40 minutes. 


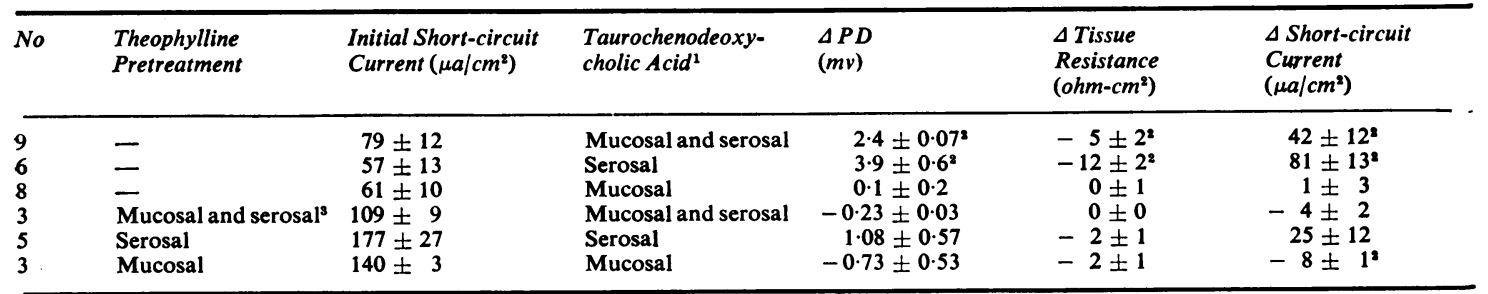

Table I Effect of taurochenodeoxycholate on transmural pd, tissue resistance, and short-circuit current

${ }^{1}$ Taurochenodeoxycholate was added to the mucosal and/or serosal solution at a final concentration of $2 \mathrm{mM}$.

${ }^{2}$ Indicates a statistically significant difference $(P<0.05)$ on the basis of a paired $t$ test. Values reported are mean $\pm S E M$. Sign of the pd change refers to the serosal solution. Changes in short-circuit current, pd, and resistance were calculated from the differences between the peak value after addition and the value immediately before the addition.

${ }^{3}$ Theophylline was added to the mucosal and/or serosal bathing solution at a final concentration of $10 \mathrm{mM}$.

\begin{tabular}{|c|c|c|c|c|c|}
\hline No & $\begin{array}{l}\text { Initial Short-circuit } \\
\text { Current }\left(\mu a / \mathrm{cm}^{2}\right)\end{array}$ & Taurocholate & $\begin{array}{l}\triangle P D \\
(m v)\end{array}$ & $\begin{array}{l}\Delta \text { Tissue Resistance } \\
\left(\mathrm{ohm}-\mathrm{cm}^{2}\right)\end{array}$ & $\begin{array}{l}\Delta \text { Short-circuit } \\
\text { Current }\left(\mu a / \mathrm{cm}^{2}\right)\end{array}$ \\
\hline $\begin{array}{l}6 \\
6 \\
4\end{array}$ & $\begin{array}{l}56 \pm 6 \\
47 \pm 10 \\
66 \pm 14\end{array}$ & $\begin{array}{l}\text { Mucosal and serosal } \\
\text { Serosal } \\
\text { Mucosal }\end{array}$ & $\begin{array}{r}1 \cdot 3 \pm 0.5^{2} \\
1.8 \pm 0.3^{2} \\
-0.2 \pm 0.1\end{array}$ & $\begin{array}{l}-5 \pm 2 \\
-3 \pm 1 \\
-2 \pm 2\end{array}$ & $\begin{array}{c}23 \pm 9^{2} \\
27 \pm 5^{2} \\
-\quad 2 \pm 2\end{array}$ \\
\hline
\end{tabular}

Table II Effect of taurocholate on transmural pd, tissue resistance, and short-circuit current

${ }^{1}$ Taurocholate was added to the mucosal and/or serosal solution at a final concentration of 2 mM. Other notation as in table $\mathrm{I}$.

\begin{tabular}{|c|c|c|c|c|c|c|c|}
\hline \multirow[t]{2}{*}{ No } & \multicolumn{2}{|c|}{ Pretreatment } & \multirow{2}{*}{$\begin{array}{l}\text { Initial Short-circuit } \\
\text { Current } \\
\left(\mu a / \mathrm{cm}^{2}\right)\end{array}$} & \multirow[t]{2}{*}{ Theophylline ${ }^{1}$} & \multirow{2}{*}{$\begin{array}{l}\triangle P D \\
(m v)\end{array}$} & \multirow{2}{*}{$\begin{array}{l}\Delta \text { Tissue } \\
\text { Resistance } \\
\left.(\text { ohm-cm })^{2}\right)\end{array}$} & \multirow{2}{*}{$\begin{array}{l}\Delta \text { Short-circuit } \\
\text { Current } \\
\left(\mu a / \mathrm{cm}^{2}\right)\end{array}$} \\
\hline & $\begin{array}{l}\text { Mucosal } \\
\text { Solution }\end{array}$ & $\begin{array}{l}\text { Serosal } \\
\text { Solution }\end{array}$ & & & & & \\
\hline $\begin{array}{l}3 \\
5 \\
3\end{array}$ & $\begin{array}{l}- \\
-\end{array}$ & - & $\begin{array}{l}50 \pm 9 \\
45 \pm 12 \\
30 \pm 4\end{array}$ & $\begin{array}{l}\text { Mucosal and serosal } \\
\text { Serosal } \\
\text { Mucosal }\end{array}$ & $\begin{array}{l}4 \cdot 2 \pm 1 \cdot 4^{2} \\
7 \cdot 4 \pm 1 \cdot 4^{2} \\
6 \cdot 4 \pm 1 \cdot 1^{2}\end{array}$ & $\begin{array}{l}-15 \pm 6 \\
-17 \pm 6^{2} \\
-29 \pm 10\end{array}$ & $\begin{array}{r}82 \pm 18^{2} \\
127 \pm 18^{2} \\
112 \pm 5^{2}\end{array}$ \\
\hline $\begin{array}{l}9 \\
6 \\
8\end{array}$ & $\begin{array}{l}\text { TCDC } \\
\text { TCDC }\end{array}$ & $\begin{array}{l}\text { TCDC } \\
\text { TCDC }\end{array}$ & $\begin{array}{l}46 \pm 9 \\
39 \pm 6 \\
25 \pm 3\end{array}$ & $\begin{array}{l}\text { Mucosal and serosal } \\
\text { Serosal } \\
\text { Mucosal }\end{array}$ & $\begin{aligned}-0.05 & \pm 0.11 \\
-0.03 & \pm 0.17 \\
2.69 & \pm 0.61^{2}\end{aligned}$ & $\begin{array}{l}-5 \pm 1^{2} \\
-6 \pm 1^{2} \\
-11 \pm 3^{2}\end{array}$ & $\begin{array}{c}7 \pm 5 \\
5 \pm 5 \\
57 \pm 8^{2}\end{array}$ \\
\hline $\begin{array}{l}6 \\
6 \\
4\end{array}$ & $\begin{array}{l}\mathrm{TC} \\
\mathrm{TC}\end{array}$ & $\begin{array}{l}\text { TC } \\
\text { TC }\end{array}$ & $\begin{array}{l}19 \pm 3 \\
30 \pm 7 \\
18 \pm 2\end{array}$ & $\begin{array}{l}\text { Mucosal and serosal } \\
\text { Serosal } \\
\text { Mucosal }\end{array}$ & $\begin{array}{l}2 \cdot 23 \pm 0.28^{2} \\
4 \cdot 28 \pm 0.33^{2} \\
4 \cdot 63 \pm 1 \cdot 18^{2}\end{array}$ & $\begin{array}{l}-19 \pm 3^{2} \\
-23 \pm 5^{2} \\
-28 \pm 6^{2}\end{array}$ & $\begin{array}{r}46 \pm 8^{2} \\
78 \pm 9^{2} \\
104 \pm 12^{2}\end{array}$ \\
\hline
\end{tabular}

Table III Effect of theophylline on transmural pd, tissue resistance, and short-circuit current with or without pretreatment with bile acids

${ }^{1}$ Theophylline was added to the mucosal and/or serosal solution at a final concentration of $10 \mathrm{mM}$. Other notation as in table $\mathrm{I}$.

the mucosal or serosal surface alone (table III). When theophylline was added after the serosal application of taurochenodeoxycholic acid neither short-circuit current nor pd increased significantly (fig 1A). Following the mucosal application of taurochenodeoxycholic acid, theophylline had a stimulatory effect (fig 1B). Pretreatment with taurocholic acid at the mucosal and/or serosal surface reduced slightly the effect of theophylline.

\section{Discussion}

Binder and Rawlins (1973) found that in in-vitro preparations of rat colonic mucosa taurochenodeoxycholic acid increased short-circuit current and pd simultaneous with decreased absorption of water and $\mathrm{NaCl}$. We have confirmed their observation on electrical effects and found also that taurodeoxycholic acid and taurocholic acid are effective. The observation that the latter increased short-circuit current and pd is difficult to reconcile with observations in vivo that this bile acid does not alter water and electrolyte absorption.

The observation that bile acids acted when applied to the serosal surface, but not when applied to the mucosal surface, of the rat colon also makes inter- 
pretation of the data from this in-vitro model difficult. Clearly, bile acids in vivo are exposed primarily to the mucosal surface of intestine, and any in-vitro action they have would be expected following mucosal, not serosal, application. Preliminary observations on rabbit ileum in vitro indicate that electrical phenomena associated with secretion can be produced when bile acids are applied to either the mucosal or serosal surface (Schwiter, Hepner, and Rose, unpublished observation). Thus, rabbit ileum may be a better model for future studies in vitro.

From the present and previous experiments (Binder and Rawlins, 1973) it appears that the increase in short-circuit current caused by conjugated dihydroxy bile acids reflects active transport of anions in the direction of secretion. Binder and Rawlins (1973) suggested that the effect of dihydroxy bile acids may be mediated by cyclic adenosine 3', 5'-monophosphate (cyclic AMP) and listed several effects of bile acids that are similar to those produced by theophylline as evidence. We have confirmed and extended these observations but a causal relationship between intracellular levels of cyclic AMP and secretion will remain a tentative conclusion until evidence is presented that cyclic AMP is stimulated at the time of the peak electrical and secretory response ${ }^{1}$.

The transitory nature of the electrical response elicited by bile acids is not readily explained from information currently available. It is unlikely to be due to cell membrane damage causing temporary potassium leakage across the serosal cell surface since the response is immediately dependent on availability of $\mathrm{O}_{2}$. A transitory electrical response was also observed in rat ileum in vitro exposed to taurocholic acid (Wall and Baker, 1974). In both tissues the response in vitro may be limited by intracellular accumulation of bile acids since a stable response was observed in vivo (Wall and Baker, 1974).

The recent observation by Wall and Baker (1974) that bile acids are effective in eliciting electrical responses in rat small intestine only when applied to the mucosal surface contrasts with our observation of an effect due to serosal application in colon. The small intestine preparation apparently was not stripped of serosa which might have prevented bile acids in the serosal bathing solution from reaching the transport cells.

${ }^{1}$ While these studies were in progress a report appeared (Binder, $\mathrm{H}$. J., Filburn, C., and Volpe, B. T. (1975), Bile salt alteration of colonic electrolyte transport: role of cyclic adenosine monophosphate. Gastroenterology, 68, 503-508) showing an increase in rat colonic mucosal cyclic AMP after incubation for 20 minutes with $2 \mathrm{mM}$ taurochenodeoxycholic acid. However, we have been unable to confirm these observations (Wade, Hepner, and Rose, unpublished observations).
The effects on epithelial transport of such agents as theophylline, bile acids, and cyclic AMP might not represent a single change in tissue properties. The decreased tissue resistance in epithelial mucosa following exposure to bile acids could be the result of tissue damage. Thus, Frizzell and Schultz (1970) observed that protein is removed from the mucosal surface of rabbit ileum exposed to taurocholic acid, and Thomas, Nahrwold, and Rose (1972) found increased amounts of phospholipid in the lumen of rat stomach exposed to taurocholic acid. In addition, it has been found that theophylline, cyclic AMP, and cholera toxin inhibit unidirectional mucosa-to-serosa fluxes of $\mathrm{Na}$ and $\mathrm{Cl}$ across rabbit ileum by interfering with membrane components involved in transport (Frizzell, Nellans, Rose, MarkscheidKaspi, and Schultz, 1973; Nellans, Frizzell, and Schultz, 1973). Thus, the final interpretation of experiments designed to study initiation of secretion must consider that alterations in transmural ionic fluxes might be the sum result of tissue destruction and inhibition of normal absorptive transport machinery as well as initiation of secretory processes.

There is currently considerable interest in using an animal model to study intestinal secretion associated with clinical diarrhoea caused by such agents as bile acids (Mekhjian and Phillips, 1970), fatty acids (Ammon and Phillips, 1974), and cholera toxin (Moore, Bieberdorf, Morawski, Finkelstein, and Fordtran, 1971). Previous reports have documented that dihydroxy bile acids in the concentrations used in the present experiments initiate electrolyte secretion by rat colonic mucosa. The present report may serve to inform concerned investigators that in the model of rat colon bile acids are effective in eliciting the electrical phenomena associated with secretion only when present at the serosal surface. The existing literature might require reinterpretation in view of this finding.

This work was supported in part by the US Public Health Service grant AM-15926.

\section{References}

Ammon, H. V., and Phillips, S. F. (1974). Inhibition of ileal water absorption by intraluminal fatty acids: influence of chain length, hydroxylation and conjugation of fatty acids. J. clin. Invest., 53, 205-210.

Binder, H. J., and Rawlins, C. L. (1973). Effect of conjugated dihydroxy bile salts on electrolyte transport in rat colon. J. clin. Invest., 52 , 1460-1466.

Field, M. (1971). Ion transport in rabbit ileal mucosa, II. Effects of cyclic 3', 5'-AMP. Amer. J. Physiol., 221, 992-1003.

Frizzell, R. A., and Schultz, S. G. (1970). Effect of bile salts on transport across brush border of rabbit ileum. Biochim. biophys. Acta. (Amst), 211, 589-592.

Frizzell, R. A. Nellans, H. N., Rose, R. C., Markscheid-Kaspi, L. and Schultz, S. G. (1973). Intracellular C1 concentrations and influxes across the brush border of rabbit ileum. Amer. J. Physiol., 224, 328-337.

Hofmann, A. F. (1967). The syndrome of ileal disease and the broken 
enterohepatic circulation: cholerheic enteropathy. Gastroenterology, 52, $752-757$.

Hofmann, A. F. (1973). Comment on letter. Gastroenterology, 65, 861. Mekhjian, H. S., and Phillips, S. F. (1970). Perfusion of the canine colon with unconjugated bile acids. Gastroenterology, 59, 120-129.

Mekhjian, H. S., Phillips, S. F., and Hofmann, A. F. (1971). Colonic secretion of water and electrolytes induced by bile acids: perfusion studies in man. J. clin. Invest., 50, 1569-1577.

Moore, W. L., Jr., Bieberdorf, F. A., Morawski, S. G., Finkelstein, R. A., and Fordtran, J. S. (1971). Ion transport during cholerainduced ileal secretion in the dog. J. clin. Invest., 50, 312-318.

Nellans, H. N., Frizzell, R. A., and Schultz, S. G. (1973), Coupled sodium-chloride influx across the brush border of rabbit ileum. Amer. J. Physiol., 225, 467-474.

Rose, R. C., Gelarden, R. T., and Nahrwold, D. L. (1973). Electrical properties of isolated human gallbladder. Amer. J. Physiol., 224, 1320-1326.

Teem, M. V., and Phillips, S. F. (1972). Perfusion of the hamster jejunum with conjugated and unconjugated bile acids; inhibition of water absorption and effects on morphology. Gastroenterology, 62, 261-267.

Thomas, A. J., Nahrwold, D. L., and Rose, R. C. (1972). Detergent action of sodium taurocholate on rat gastric mucosa. Biochim. Biophys. Acta (Amst.), 282, 210-213.

Wall, M. J., and Baker, R. D. (1974). Intestinal transmural electrical properties: effects of conjugated bile salt in vitro. Amer. $J$. Physiol., 227, 499-506.

Wingate, D. L., Phillips, S. F., and Hofmann, A. F. (1973). Effect of glycine-conjugated bile acids with and without lecithin on water and glucose absorption in perfused human jejunum. J. clin. Invest., 52, 1230-1236. 